\title{
Possible role of low-dose etoposide therapy for hemophagocytic lymphohistiocytosis by COVID-19
}

\author{
Akiyoshi Takami ${ }^{1}$ i \\ Received: 24 April 2020 / Revised: 28 April 2020 / Accepted: 1 May 2020 / Published online: 12 May 2020 \\ (c) Japanese Society of Hematology 2020
}

Dear the Editor,

Among patients infected with severe acute respiratory syndrome coronavirus 2 (SARS-CoV-2), up to $20 \%$ develop a severe form of coronavirus disease 2019 (COVID-19) with dyspnea and hypoxia, and one-quarter of those patients develop acute respiratory distress syndrome (ARDS) in a median of 2.5 days, with a mortality rate of up to $50 \%$ (range, 16-78\%) [1-4]. Effective treatment is thus urgently needed.

Huang et al. [5] reported that the severity of COVID-19 is associated with increased levels of inflammatory cytokines such as IL-1, IL-6, and tumor necrosis factor- $\alpha$ (TNF $\alpha)$, which resembles the cytokine profile observed in cases of secondary hemophagocytic lymphohistiocytosis (sHLH) and macrophage activation syndrome (MAS) [6]. This is supported by a recent report by Mehta et al. [7] in which all 35 patients with severe COVID-19 showed hemophagocytosis on bone marrow aspirates, cytopenia of two or more lineages, and increased serum ferritin levels $(\geq 2000 \mathrm{ng} / \mathrm{mL})$. Control of hypercytokinemia is key to successfully treating sHLH/MAS. However, the effectiveness of cytokine blocking with anti-IL-1 and anti-IL-6 on sHLH/MAS has been limited [6].

The most common trigger for sHLH/MAS is a viral infection, which stimulates macrophages to release inflammatory cytokine and perform phagocytosis of virus-infected cells. Cytotoxic T lymphocytes (CTLs) are subsequently activated through their antigen-presenting function, and hypercytokinemia occurs, resulting in virus-infected cells undergoing perforin-mediated cell lysis. Finally, the activated CTLs selectively eliminate the activated macrophages, and sHLH/MAS naturally resolves [8]. However, unlike other

Akiyoshi Takami

takami-knz@umin.ac.jp

1 Division of Hematology, Department of Internal Medicine, Aichi Medical University School of Medicine, 1-1 Yazakokarimata, Nagakute 480-1195, Japan virus infections, Epstein-Barr virus (EBV) initially activates CTLs to induce hypercytokinemia directly and indirectly, thereby allowing for prolonged antigen presentation by macrophages, which causes CTLs to fail to eliminate activated macrophages; this lack of normal feedback regulation results in excessive macrophage activity and hypercytokinemia, thereby leading to the development of organ damage, cytopenia, and coagulopathy [8] (Fig. 1). It is reasonable to assume that COVID-19 causes a similar pathophysiology to EBV-associated sHLH/MAS, as there are common abnormalities in both diseases, such as hypercytokinemia, macrophage activation, cytopenias, immunological abnormalities in CD8-positive cells, and the rapid development and progression of organ damage and coagulopathy $[1,2$, $5,7,9]$.

Etoposide is a chemotherapeutic drug widely used to treat various types of cancer, including lymphoma, leukemia, and lung cancer, and promotes apoptosis of cancer cells by inhibiting the topoisomerase II enzyme. Etoposide is also known to be effective at low doses in combination with cyclosporine and steroids for familial HLH [10]. However, such combination therapy may be too immunosuppressive to eliminate virus-infected cells in cases of virus-associated sHLH/MAS. Low-dose etoposide monotherapy, e.g. a single dose of $100-150 \mathrm{mg} / \mathrm{m}^{2}, 1-3$ cycles, has been successfully used to treat sHLH/MAS associated with EBV and autoimmune diseases, such as juvenile rheumatoid arthritis, with a response rate of $\geq 80 \%$ reported $[8,11,12]$. Evidence supporting the usefulness of etoposide treatment for sHLH/MAS can also be seen in a previous report [13], in which low-dose etoposide substantially alleviated all symptoms of murine HLH and prolonged the survival through the selective depletion of activated CTLs and suppression of their inflammatory cytokine production. Importantly, low-dose etoposide essentially spares quiescent naïve and memory $\mathrm{T}$ cells while ablating activated $\mathrm{T}$ cells $[13,14]$. In another mouse model study [15], the combination of low-dose etoposide and prednisolone improved the survival 


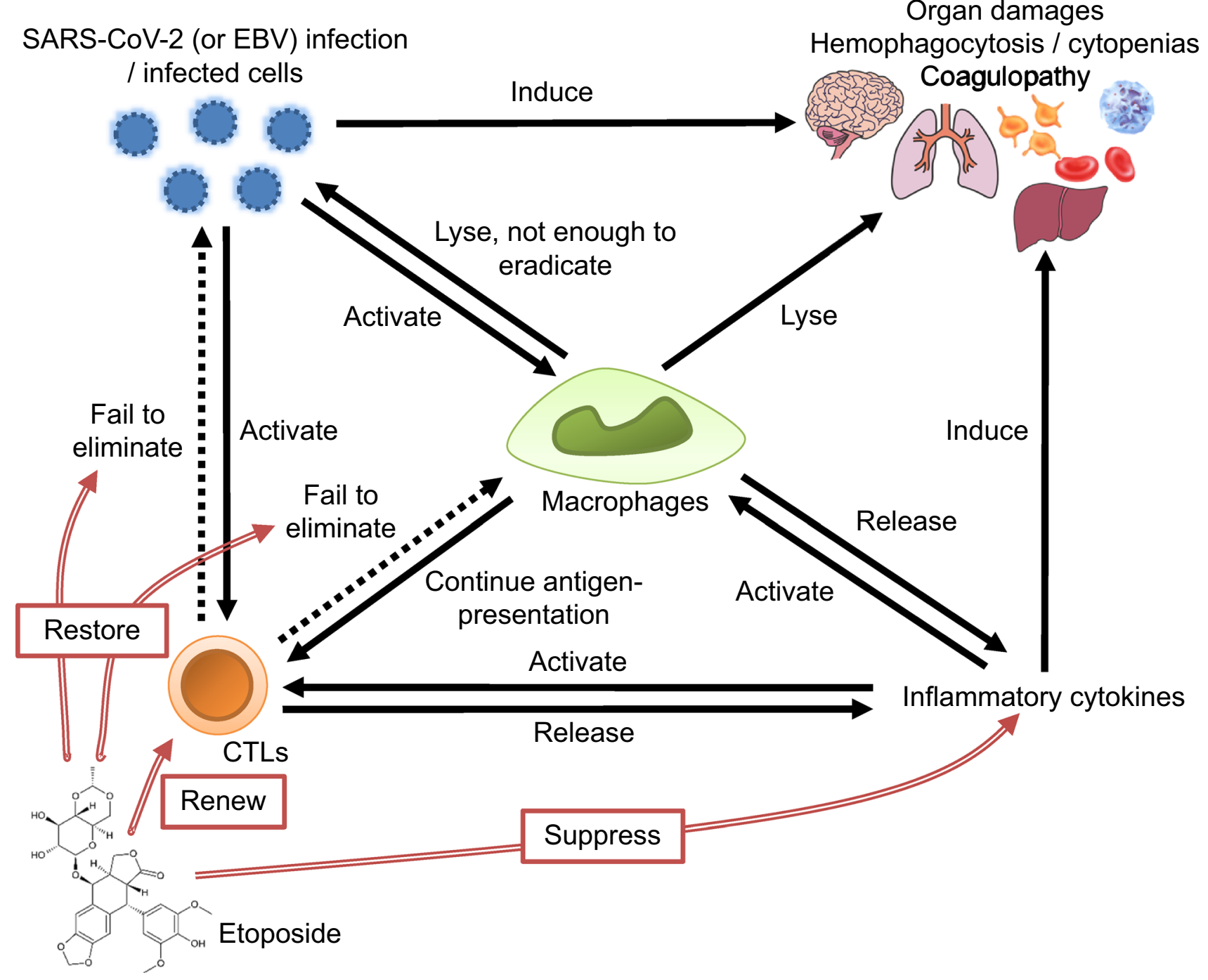

Fig. 1 Macrophage activation syndrome by COVID-19 and its treatment with low-dose etoposide (author's hypothesis). Low-dose etoposide is considered to restore immunological homeostasis by depleting activated CTLs and suppressing their production of inflammatory

rate of fatal ARDS model mice with hypercytokinemia and hemophagocytosis, which were induced by administration of $\alpha$-galactosylceramide and lipopolysaccharide, through suppressing the intrapulmonary recruitment and activation of macrophages, T cells, NK cells, and neutrophils. Low-dose etoposide monotherapy also improved pulmonary edema. Besides, the early introduction of low-dose etoposide was found to be effective in patients with EBV-related sHLH/ MAC with respiratory failure [16]. These findings suggest that low-dose etoposide improves hypercytokinemia, renew CTLs so that activated macrophages and SARS-CoV2-infected cells are eliminated, and thus immunomodulatory abnormalities associated with SARS-CoV-2 infection are restored, potentially improving COVID-19 with ARDS (Fig. 1). cytokines, which reduces the activity of macrophages and leads to the elimination of activated macrophages and SARS-CoV-2-infected cells by newly activated CTLs

Like other chemotherapeutic agents, the major adverse effects of etoposide are associated with off-target genotoxicity, dose-dependent myelosuppression and risks of secondary cancer. However, treatment with low-dose etoposide for sHLH/MAS induced little hematologic toxicity, instead of resulting in hematological improvement by restoring the bone marrow function $[8,11,12]$, and only 2 of over 600 patients who received low-dose etoposide developed malignancies [10], supporting the use of low-dose etoposide for the treatment of benign diseases. Moreover, the administration of up to five doses of lowdose etoposide therapy to an adult costs approximately $\$ 80$ (as of April 21, 2020), while a single dose of tocilizumab, a humanized monoclonal antibody against the IL-6 receptor, costs $\$ 1000$. 
Given the above, the use of low-dose etoposide for severe COVID-19 may compensate for the immunoregulatory aberration and macrophage activation causing the organ damage, coagulopathy, and cytopenia, thereby leading to the restoration of homeostasis and hopefully reduction in the mortality and morbidity rates. Given the high efficacy and safety of low-dose etoposide for sHLH/MAS and the staggering mortality rate (as high as 50\%) associated with severe COVID19 , this monotherapy is worth considering as a treatment for such patients.

Author contribution AT wrote the manuscript.

Funding There is no funding involved in the manuscript.

\section{Compliance with ethical standards}

Conflict of interest The author reports no potential conflict of interest.

\section{References}

1. Zhou F, Yu T, Du R, Fan G, Liu Y, Liu Z, et al. Clinical course and risk factors for mortality of adult inpatients with COVID19 in Wuhan, China: a retrospective cohort study. Lancet. 2020;395(10229):1054-62. https://doi.org/10.1016/S0140 -6736(20)30566-3.

2. Wang F, Nie J, Wang H, Zhao Q, Xiong Y, Deng L, et al. Characteristics of peripheral lymphocyte subset alteration in COVID-19 pneumonia. J Infect Dis. 2020. https://doi.org/10.1093/infdis/jiaa1 50 .

3. Grasselli G, Pesenti A, Cecconi M. Critical care utilization for the COVID-19 outbreak in Lombardy, Italy: early experience and forecast during an emergency response. JAMA. 2020. https://doi. org/10.1001/jama.2020.4031.

4. Arentz M, Yim E, Klaff L, Lokhandwala S, Riedo FX, Chong $\mathrm{M}$, et al. Characteristics and outcomes of 21 critically ill patients with COVID-19 in Washington State. JAMA. 2020. https://doi. org/10.1001/jama.2020.4326.

5. Huang C, Wang Y, Li X, Ren L, Zhao J, Hu Y, et al. Clinical features of patients infected with 2019 novel coronavirus in Wuhan, China. Lancet. 2020;395(10223):497-506. https://doi. org/10.1016/S0140-6736(20)30183-5.

6. Bode SF, Lehmberg K, Maul-Pavicic A, Vraetz T, Janka G, Stadt UZ, et al. Recent advances in the diagnosis and treatment of hemophagocytic lymphohistiocytosis. Arthritis Res Ther. 2012;14(3):213. https://doi.org/10.1186/ar3843.
7. Mehta P, McAuley DF, Brown M, Sanchez E, Tattersall RS, Manson JJ, et al. COVID-19: consider cytokine storm syndromes and immunosuppression. Lancet. 2020;395(10229):1033-4. https:// doi.org/10.1016/S0140-6736(20)30628-0.

8. Morimoto A, Nakazawa Y, Ishii E. Hemophagocytic lymphohistiocytosis: pathogenesis, diagnosis, and management. Pediatr Int. 2016;58(9):817-25. https://doi.org/10.1111/ped.13064.

9. Zhang Y, Xiao M, Zhang S, Xia P, Cao W, Jiang W, et al. Coagulopathy and antiphospholipid antibodies in patients with Covid19. N Engl J Med. 2020;382(17):e38. https://doi.org/10.1056/ NEJMc2007575.

10. Bergsten E, Horne A, Arico M, Astigarraga I, Egeler RM, Filipovich $\mathrm{AH}$, et al. Confirmed efficacy of etoposide and dexamethasone in HLH treatment: long-term results of the cooperative HLH-2004 study. Blood. 2017;130(25):2728-38. https://doi. org/10.1182/blood-2017-06-788349.

11. Koyama M, Sawada A, Yasui M, Inoue M, Kawa K. Encouraging results of low-dose etoposide in the treatment of early-onset hemophagocytic syndrome following allogeneic hematopoietic stem cell transplantation. Int J Hematol. 2007;86(5):466-7. https ://doi.org/10.1007/BF02984009.

12. Arca M, Fardet L, Galicier L, Riviere S, Marzac C, Aumont C, et al. Prognostic factors of early death in a cohort of 162 adult haemophagocytic syndrome: impact of triggering disease and early treatment with etoposide. Br J Haematol. 2015;168(1):63-8. https ://doi.org/10.1111/bjh.13102.

13. Johnson TS, Terrell CE, Millen SH, Katz JD, Hildeman DA, Jordan MB. Etoposide selectively ablates activated T cells to control the immunoregulatory disorder hemophagocytic lymphohistiocytosis. J Immunol. 2014;192(1):84-91. https://doi.org/10.4049/ jimmunol.1302282.

14. Ferraro C, Quemeneur L, Fournel S, Prigent AF, Revillard JP, Bonnefoy-Berard $\mathrm{N}$. The topoisomerase inhibitors camptothecin and etoposide induce a CD95-independent apoptosis of activated peripheral lymphocytes. Cell Death Differ. 2000;7(2):197-206. https://doi.org/10.1038/sj.cdd.4400595.

15. Aoyagi T, Sato Y, Toyama M, Oshima K, Kawakami K, Kaku M. Etoposide and corticosteroid combination therapy improves acute respiratory distress syndrome in mice. Shock. 2019;52(1):83-91. https://doi.org/10.1097/SHK.0000000000001231.

16. Imashuku S, Kuriyama K, Teramura T, Ishii E, Kinugawa N, Kato $\mathrm{M}$, et al. Requirement for etoposide in the treatment of EpsteinBarr virus-associated hemophagocytic lymphohistiocytosis. J Clin Oncol. 2001;19(10):2665-73. https://doi.org/10.1200/ JCO.2001.19.10.2665.

Publisher's Note Springer Nature remains neutral with regard to jurisdictional claims in published maps and institutional affiliations. 